\title{
Study on the influencing factors and efficiency of small and medium- sized enterprises' energy conservation and emission reduction
}

\author{
Zhiguo Fan, Ping Zhang
}

School of Management, Tianjin University of Technology, Tianjin, 300384, China

\begin{abstract}
Keywords: Energy conservation and emissions reduction efficiency; DEA; correlation analysis.
\end{abstract}
\begin{abstract}
DEA) method, 30 provinces (autonomous regions and municipalities directly under the central government) in China's small and medium-sized enterprises made an evaluation of the efficiency of energy conservation and emissions reduction, calculates and analyses the non DEA effective province small and medium-sized enterprises energy conservation and emissions reduction potential of space. Through the correlation analysis between variables, it is concluded that the technology level of development of small and medium-sized enterprises, the development scale and industrial structure is having a significant impact on energy conservation and emissions reduction efficiency factors. Finally, according to the result of empirical study, this paper puts forward policy Suggestions.
\end{abstract}

\section{The introduction}

As an inevitable problem in the process of economic development, energy conservation and emissions reduction is gradually become the focus of the central government and the social from all walks of life universal attention question. Europe and the United States is the world's energy consumption power, are of the utmost importance to energy conservation and emissions reduction work. And build a perfect legal system standard system, such as "policy", make the enterprise according to the energy conservation and emissions reduction. On the running mechanism of energy saving and emission reduction, and at the same time play to the role of the government and market, the good experience for our country provides a good reference.

Large number of small and medium-sized enterprises in our country, at the same time due to the small and medium-sized enterprises process equipment, high energy consumption, pollution, inadequate energy conservation and emissions reduction, energy conservation and emissions reduction foundation weak, causing higher total energy consumption and pollution emissions. For the management of the small and medium-sized enterprises implement effective energy saving and emission reduction, this paper USES the data envelopment analysis (DEA) method for the provinces in our country small and medium-sized enterprises to study the efficiency of energy conservation and emissions reduction, and then using the correlation analysis technology for small and medium-sized enterprises, this paper analyzes the factors which influence the efficiency of the energy conservation and emissions reduction, and proposes the corresponding countermeasures.

\section{The literature review}

Under low carbon economy era, the strategy choices of energy conservation and emissions reduction behavior constitutes the enterprise's chance of a new round of competitive advantage. Europe and the United States economy since the $1970 \mathrm{~s}$ oil crisis in the developed countries began to attach importance to energy conservation and emissions reduction work, previous studies mainly for energy efficiency, a great deal of research about the energy conservation and emissions reduction focused on the recent years. Bojic and Panos earlier study of energy conservation and emission reduction two concepts at the same time. Jirl and Frideler summary analysis was carried out on the international conference on energy conservation and emissions reduction, reiterated the importance of energy conservation and emissions reduction. Currently abroad on energy conservation and emissions reduction research mainly focus on energy conservation and emission reduction policy, the market for energy conservation and emissions reduction method, the efficiency of energy saving and 
emission reduction, etc. Domestic scholars in draw lessons from foreign mature theory on the basis of, since the early $1980 \mathrm{~s}$, the "energy resources rational exploitation and utilization of environmental protection and sustainable development and other aspects of the theoretical research and discussion. In recent years, studies of energy efficiency and energy conservation and emissions reduction efficiency become the research hot spot in China. Many scholars efficiency evaluation model based on DEA method to establish the different. Wei Chu, shen hong, wen-qiang he and full ming-xing wang using DEA method, on the basis of the data in the successive years in various provinces, the provincial energy efficiency was calculated, overall, the energy efficiency change trend in the 10 years in accordance with the characteristics of" inverted U ".

Through the energy conservation and emissions reduction efficiency research literature can be found, mainly for regional comprehensive economic evaluation object, or some key industries, study of scale feature of small and medium-sized enterprises are very rare. Based on the provincial small and medium-sized enterprises as the research object, on the energy conservation and emissions reduction efficiency and existing problems for research. And in the provinces of small and mediumsized enterprise energy-saving efficiency index as the dependent variable, related factors as explanatory variables, main influence factors of energy conservation and emissions reduction efficiency analysis of small and medium-sized enterprises, and discusses the effective ways to promote energy conservation and emissions reduction efficiency accordingly.

\section{Research methods and index selection}

Data envelopment analysis (DEA), which is based on linear programming ideas to evaluate relative efficiency between each unit, the method in evaluating the efficiency of the complex multiple input multiple output system has particular advantage. Therefore, this article USES the data envelopment analysis (DEA) method for small and medium-sized enterprises to evaluate the efficiency of energy saving and emission reduction and analysis. Based on the characteristics of the object of study and research purposes, based on the extended DEA model, the super efficiency DEA (super efficiency DEA) evaluation model. Because the super efficiency DEA model to fully sort of evaluation unit, to overcome the defects of the traditional model of effective unit does not distinguish between. Due to the pursuit of energy conservation and emissions reduction under the condition of output must minimize energy consumption and pollutant emissions, so this article choose investment orientation of super efficiency DEA model.

Draw lessons from existing literature research, this article choose input-output index in index as the labor, capital, energy investment, pollutant emissions; Industrial GDP output indicators for the provinces of direct selling enterprises.

\section{An empirical analysis of the four, small and medium-sized enterprises energy conservation and emissions reduction efficiency}

In this paper, the industrial area as the research object, in the provinces of the small and mediumsized industrial enterprises as evaluation unit. Because of the lacking of individual provinces (such as Tibet) data, this paper chose the mainland except Tibet 30 provinces, autonomous regions and municipalities directly under the central government as evaluation unit.

In this paper, the data from 2008-2010 \# China statistical yearbook, China's small and mediumsized enterprise yearbook and statistical yearbook of each province. Through correlation analysis, the employees, assets input index and output index of correlation coefficient. Greater than 0.7 , the energy consumption index and output index of correlation coefficient were greater than 0.65 , two pollutants index and output index of correlation coefficient reached more than 0.6 level, show that the correlation of the input index and output index is stronger, and is ideal to choose the index system.

From the point of economic regions, the eastern region of small and medium-sized enterprises have maintained a good momentum of development with high efficiency, energy saving and emission reduction in addition to the east of fujian, hainan provinces are DEA effective continuously, and the top. Small and medium-sized enterprise development in central China in the medium level, efficiency, 
energy saving and emission reduction DEA efficient provinces account for about half; In the western region development of small and medium-sized enterprises is weak, low efficiency, energy saving and emission reduction to only a few such as yunnan and guizhou provinces to DEA effective. In energy conservation and emissions reduction efficiency low of the provinces, shanxi, sichuan, Anhui, chongqing, such as high investment, low efficiency model, energy conservation and emissions reduction potential is bigger; Other provinces such as xinjiang, ningxia, guangxi, qinghai belongs to low investment, low efficiency model! The provinces economic development relative lag, low efficiency of energy and environment, pay special attention to it.

Table 1. 2010 years the provincial super efficiency DEA values for energy conservation and emissions reduction

\begin{tabular}{|c|c|c|c|c|c|}
\hline Province & $\theta$ & ranking & Province & $\theta$ & ranking \\
\hline Beijing & $202.93 \%$ & 1 & hebei & 101.71 & 16 \\
\hline zhejiang & $199.25 \%$ & 2 & jiangxi & $97.22 \%$ & 17 \\
\hline yunnan & $182.66 \%$ & 3 & fujian & $96.75 \%$ & 18 \\
\hline tianjin & 136.53 & 4 & heilongjiang & $95.12 \%$ & 19 \\
\hline Shanghai & $136.03 \%$ & 5 & liaoning & $93.33 \%$ & 20 \\
\hline Inner Mongolia & $135.59 \%$ & 6 & gansu & $92.35 \%$ & 21 \\
\hline shandong & $126.29 \%$ & 7 & shaanxi & $90.06 \%$ & 22 \\
\hline guangdong & $119.16 \%$ & 8 & qinghai & $88.85 \%$ & 23 \\
\hline hainan & $117.88 \%$ & 9 & anhui & $87.23 \%$ & 24 \\
\hline henan & $117.04 \%$ & 10 & sichuan & $83.15 \%$ & 25 \\
\hline hunan & $117.80 \%$ & 11 & guangxi & $81.22 \%$ & 26 \\
\hline jilin & $114.87 \%$ & 12 & chongqing & $78.68 \%$ & 27 \\
\hline jiangsu & $110.67 \%$ & 13 & ningxia & $75.44 \%$ & 28 \\
\hline guizhou & $106.47 \%$ & 14 & xinjiang & $65.89 \%$ & 29 \\
\hline hubei & $104.33 \%$ & 15 & shanxi & $65.41 \%$ & 30 \\
\hline
\end{tabular}

\section{The small and medium-sized enterprise the influence factors of energy efficiency analysis}

There are many factors that influence efficiency of energy conservation and emissions reduction, but most researchers think: technological progress, management system, economic scale, and department structure are the main factors influencing the efficiency of energy conservation and emissions reduction. Technological progress is widely research by scholars at home and abroad of energy conservation and emissions reduction factors. Technology can improve the utilization rate of natural resources, make saving and recycling of abundant resources, so as to reduce consumption of natural resources in the context of the given output, improve energy efficiency; Under the condition of a certain scale and technology, effective management and control can improve the efficiency of energy conservation and emissions reduction, energy conservation and emissions reduction in small and medium enterprises around the policy making, enforcement and management level there are big differences, these differences are also one of the main factors that lead to energy conservation and emissions reduction efficiency difference; With the overall scale of small and medium-sized enterprises, local governments can be centrally managed by setting up a park, provides the energy supply technical service support, environmental protection, and guide small and medium-sized enterprises or between small and medium-sized enterprises and large enterprises to establish a stable industry chain, strengthen management, improve the efficiency of production and energy conservation and emissions reduction; Industrial structure is the division of the national economy structure, is refers to the national economy in various sectors and between various industry departments. Because internal departments and industry growth efficiency and energy saving and emission reduction system differences, when the efficiency of energy and environment elements from 
low efficiency or the department to efficiency or efficiency of slow growth in faster-growing sector transfer, will promote composed of various departments of the economy's total efficiency energy saving and emission reduction. Therefore this paper holds that to improve the efficiency of small and medium-sized enterprise energy conservation and emissions reduction, must start from these four factors. Among them, the technological progress, management system and economies of scale and efficiency, energy saving and emission reduction division structure is negatively related to the efficiency of energy conservation and emissions reduction.

According to the results of correlation analysis, the following conclusions: Technology coefficient and the efficiency of the energy conservation and emissions reduction simple Pearson correlation coefficient is 0.802 , the probability of 0.031 , less than 0.05 , shows that there is strong positive correlation, support the original assumption 1, indicates that the development of small and mediumsized enterprise production technology and application are the important factors influencing the efficiency of energy conservation and emissions reduction; By the same token, the hypothesis 2 and hypothesis 3 and hypothesis 4 was verified.

\section{The conclusion and the suggestion}

In this paper, based on the above research related conclusions. Small and medium-sized enterprises in our country for energy conservation and emissions reduction efficiency obvious regional differences, the eastern region is better, in the central region is the medium level, low efficiency in the western region of China, technology, management, scale and industrial structure of the four factors on the small and medium-sized enterprises is significantly influenced the efficiency of energy saving and emission reduction.

Therefore, our country should take powerful measures to quickly improve the central and western regions of small and medium-sized enterprise efficiency, energy saving and emission reduction to reduce regional differences; Guide the enterprise to change the traditional management pattern, vigorously develops the circulation economy; For small and medium-sized enterprise research and development and introduction of energy conservation and environmental protection production technology of financial support, and strengthen the system construction, the energy consumption and emissions of different small and medium-sized enterprises implement classified management system, rules of different consumption standards; As soon as possible, set up market operation mechanism of the energy conservation and emissions reduction, give full play to the role of market mechanism; The experience of European and American countries of ancient bronze mirror, strengthen and improve industry group in the role of small and medium-sized enterprise management of energy conservation and emissions reduction.

\section{Reference}

[1] Chun-you wu, xianguang guo .Energy efficiency evaluation model based on super efficiency DEA research [J], journal of management, 2009, 6(11):1460-1465

[2] Jirl Klemes, Ferene Frideler. Advances in process integration, energy saving and emissions reduction [J].Applied Thermal Engineering, 2010 (1):1-5

[3] Ke-liang wang, bao-chen Yang, Winston based on the environmental effects of China's energy efficiency and energy conservation and emissions reduction potential analysis $[\mathrm{J}]$, management review, 2012, 24(8):40-50

[4] Wei Chu, shen hong. Productivity, energy efficiency and energy based on the provincial data comparison of DEA method [J], the number of economic and technical economic study, 2007 (9):111-121

[5] Zhang lei, huang yuanxi. China's industrial structure and energy saving potential analysis [J], China soft science, 2008(5):27-54 